
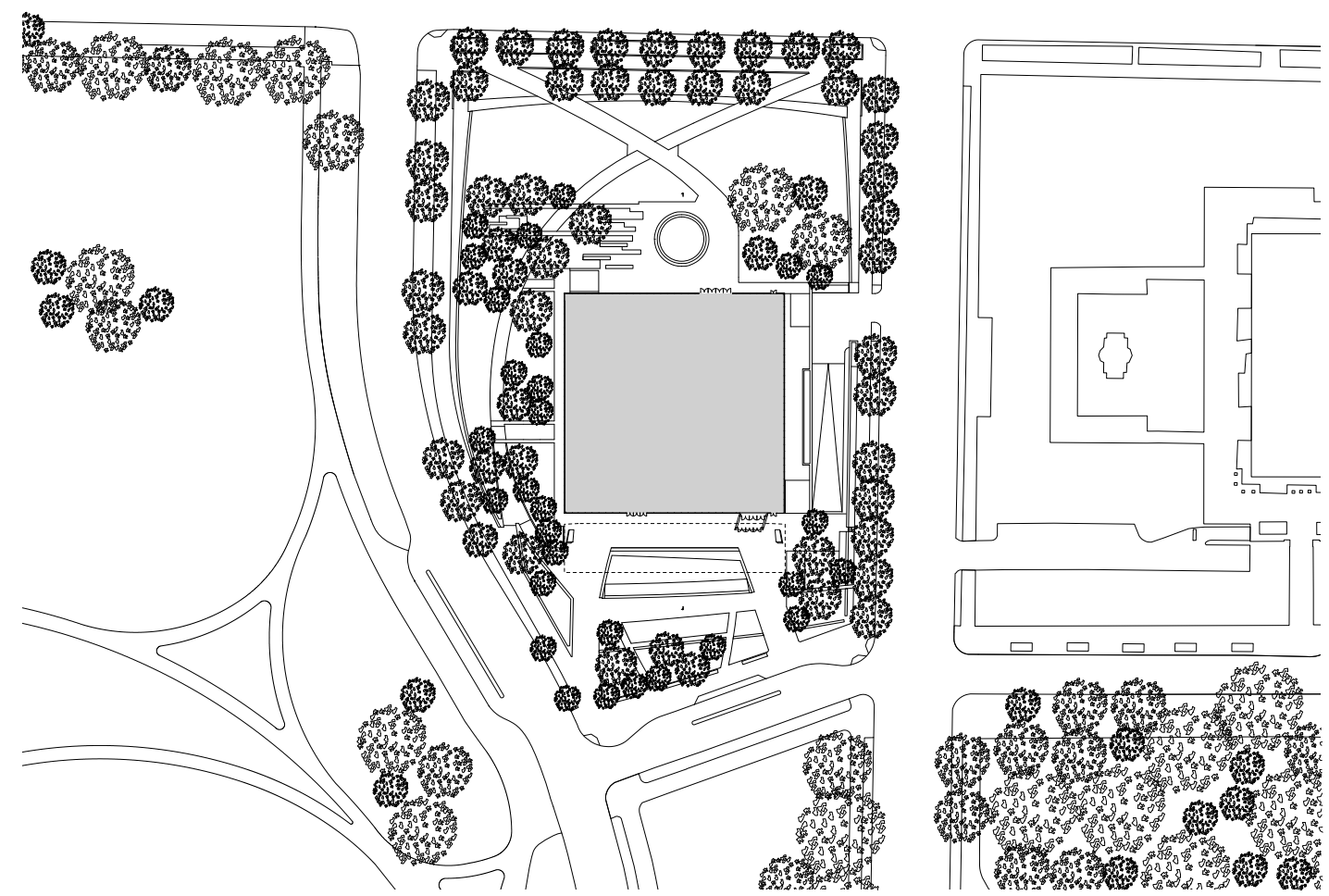

ocated on Constitution Avenue, adjacent to

the National Museum of American History and the Washington Monument, the National Museum of African American History and Culture (NMAAHC) houses exhibit galleries, administrative spaces, theatre space and collection storage space. The approach has been to establish both a meaningful relationship to this unique site as well as a strong conceptual resonance with America's deep and longstanding African heritage. The design rests on three cornerstones: the 'corona' shape of the building; the extension of the building out into the landscape - the porch; and the bronze filigree envelope.

Situated on the Washington Monument grounds, more than half of the museum is below ground with only five stories above surface. The corona is based on elements of the Washington Monument, closely matching the 17-degree angle of the capstone, while the panel size and pattern has been developed using the Monument stones as a reference. The entire building is wrapped in an ornamental bronze-coated aluminum lattice that is a historical reference to African American craftsmanship. The density of the pattern can be modulated to control the amount of sunlight and transparency into the interior. The south entry is composed of the porch and a central water feature. As 

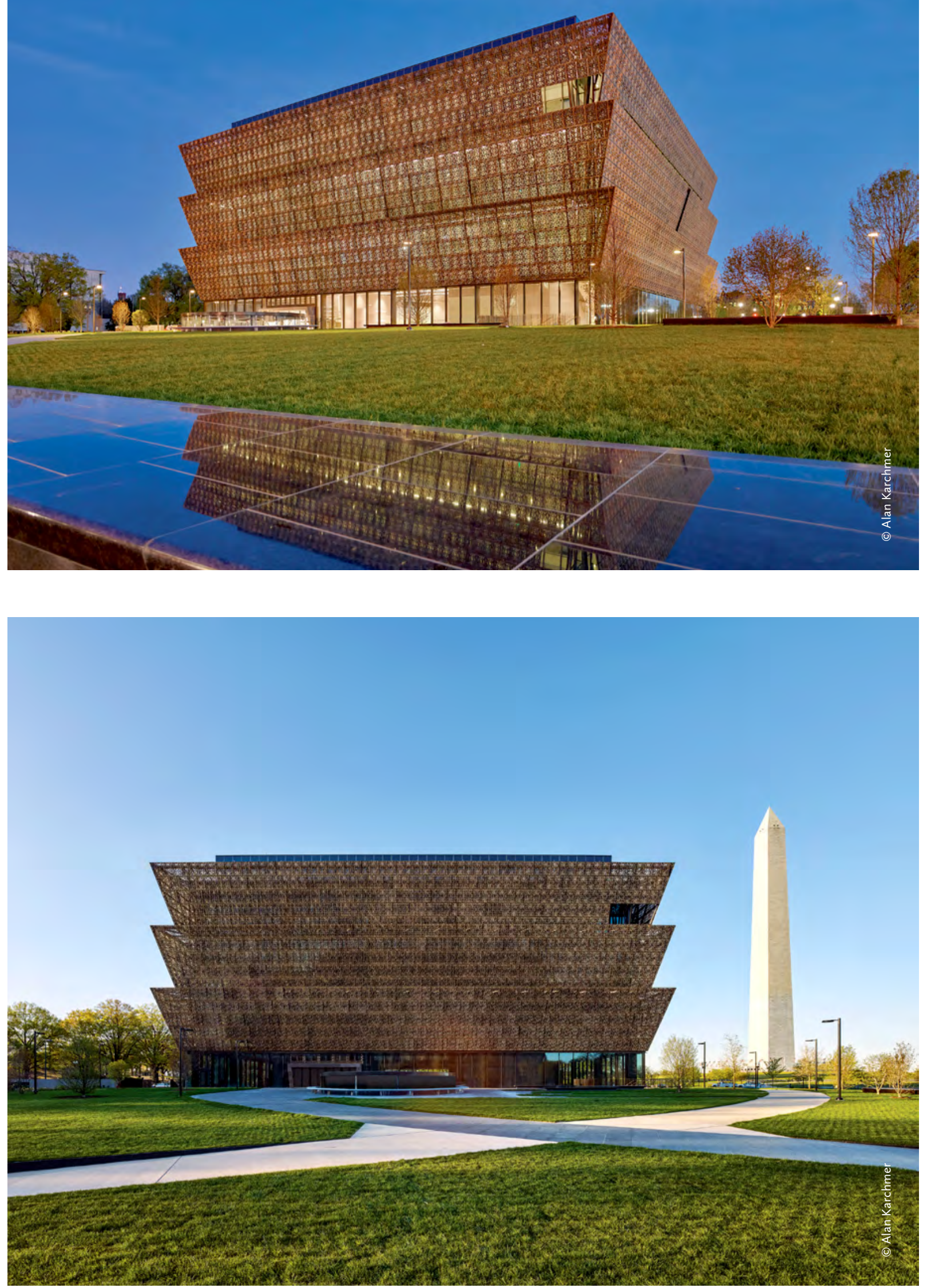


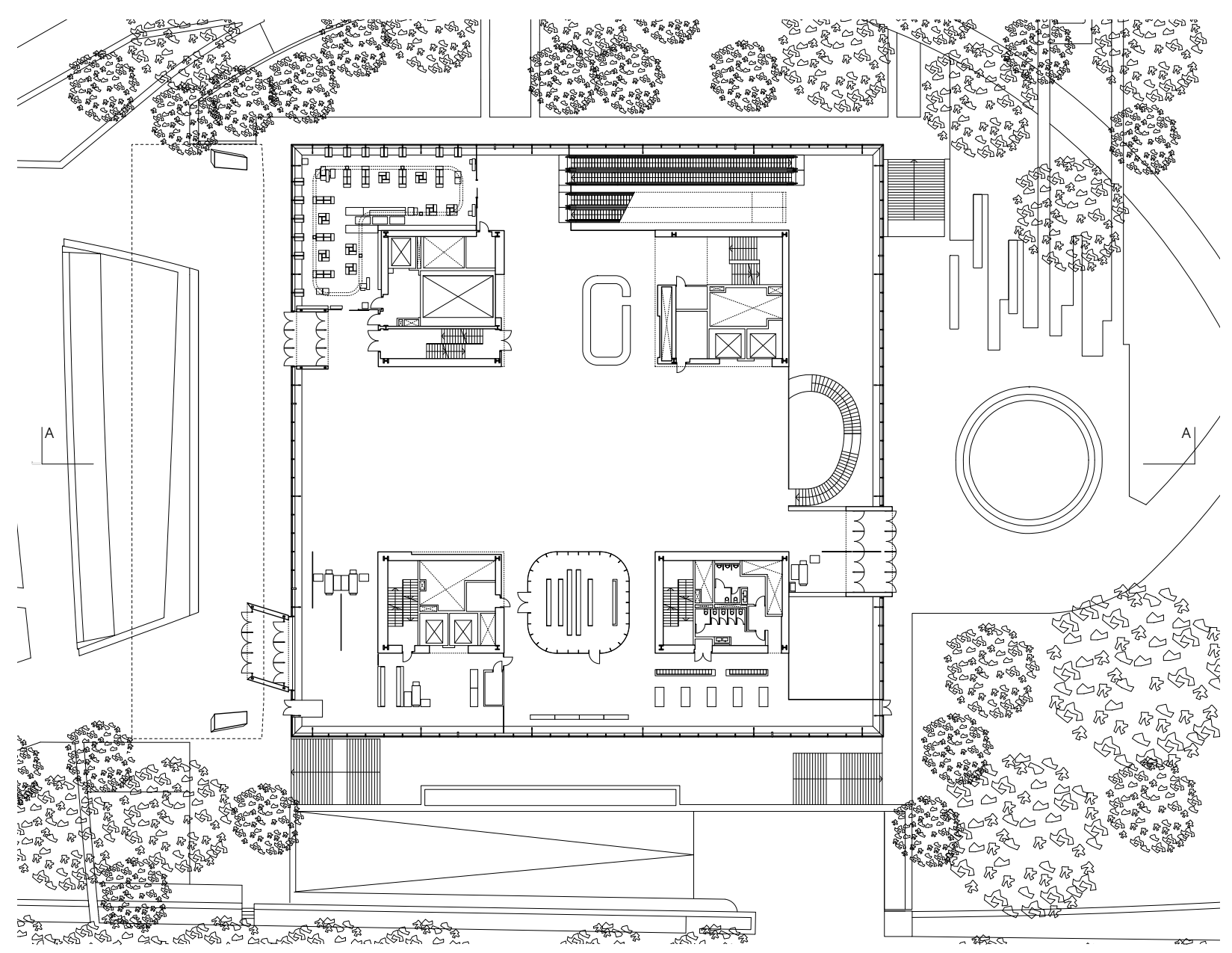

Corte AA / Section AA

E. / S. 1: 750
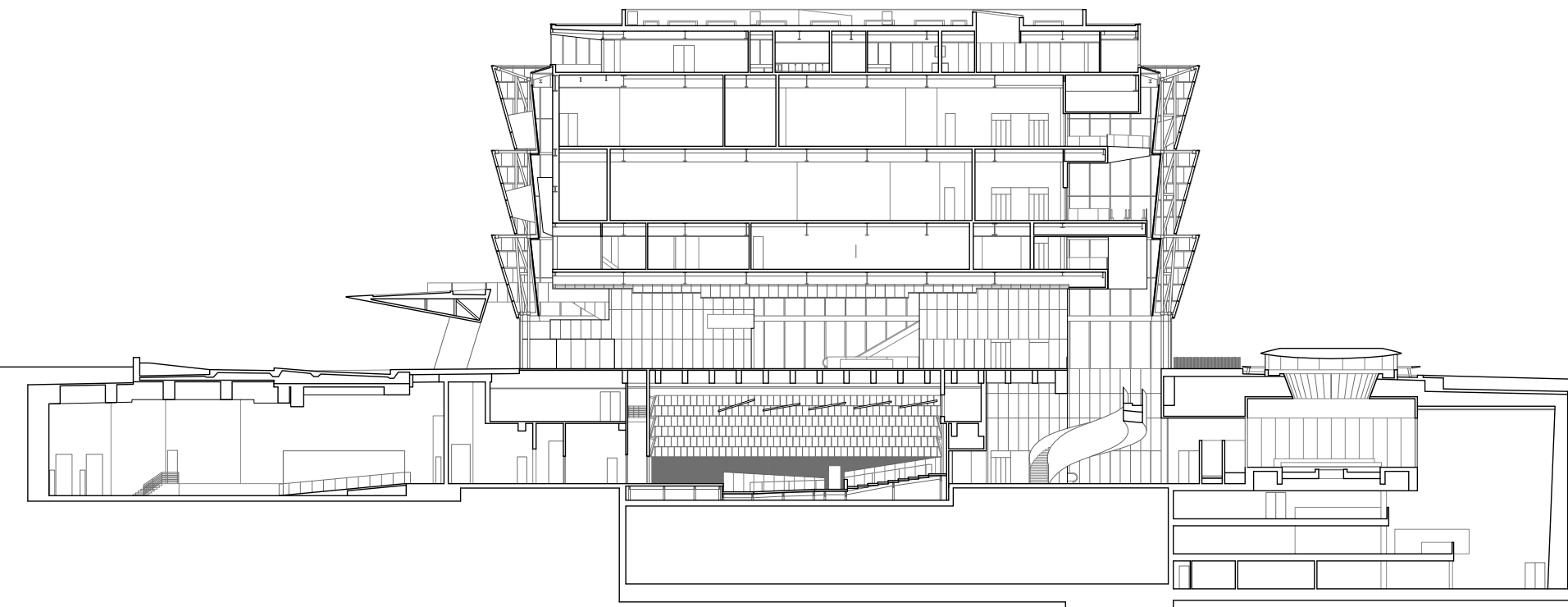
Planta primer nivel / First floor plan

E. / S. 1: 750

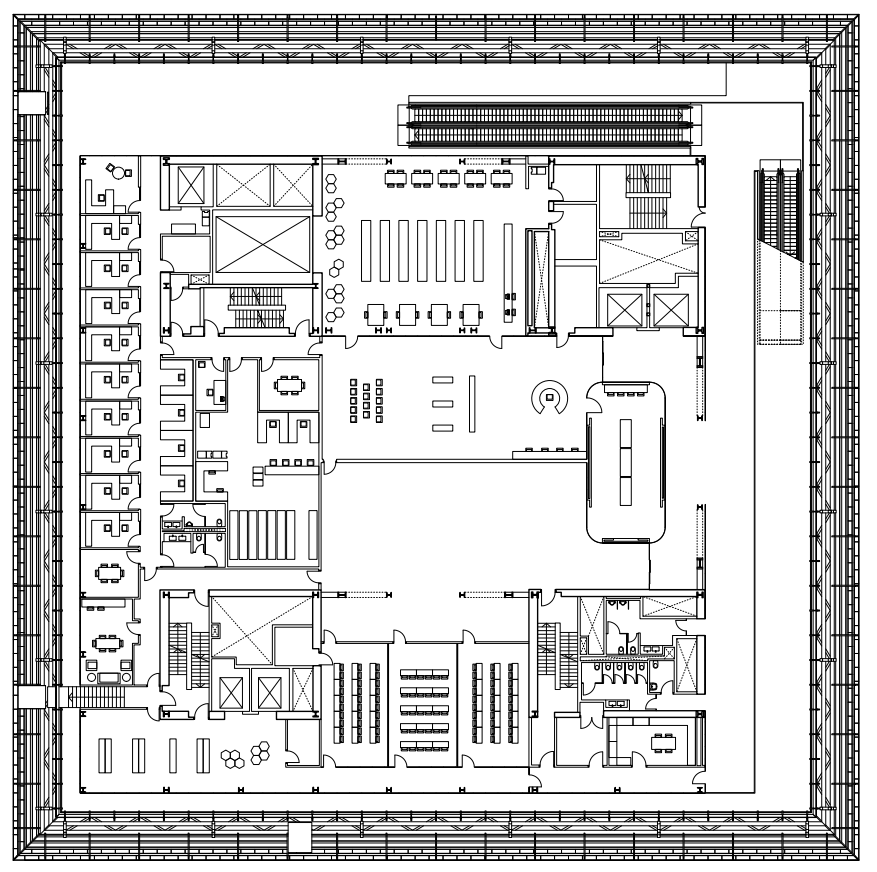

Planta tercer nivel / Third floor plan

E. / S. 1: 750

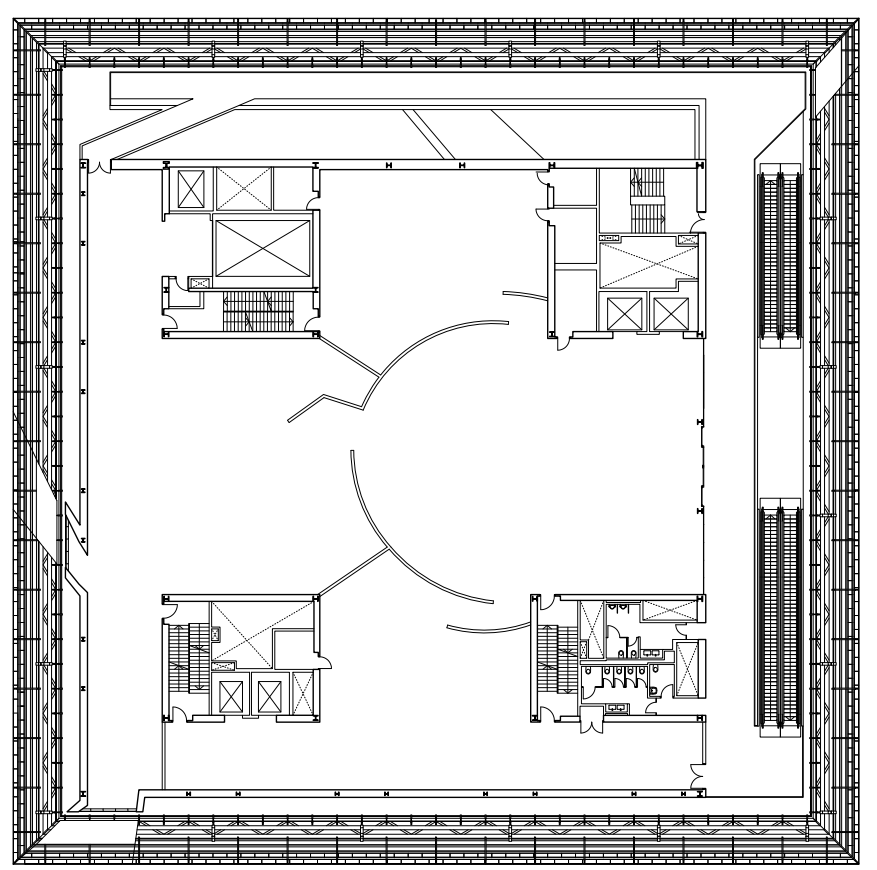

Planta segundo nivel / Second floor plan

E. / S. 1: 750

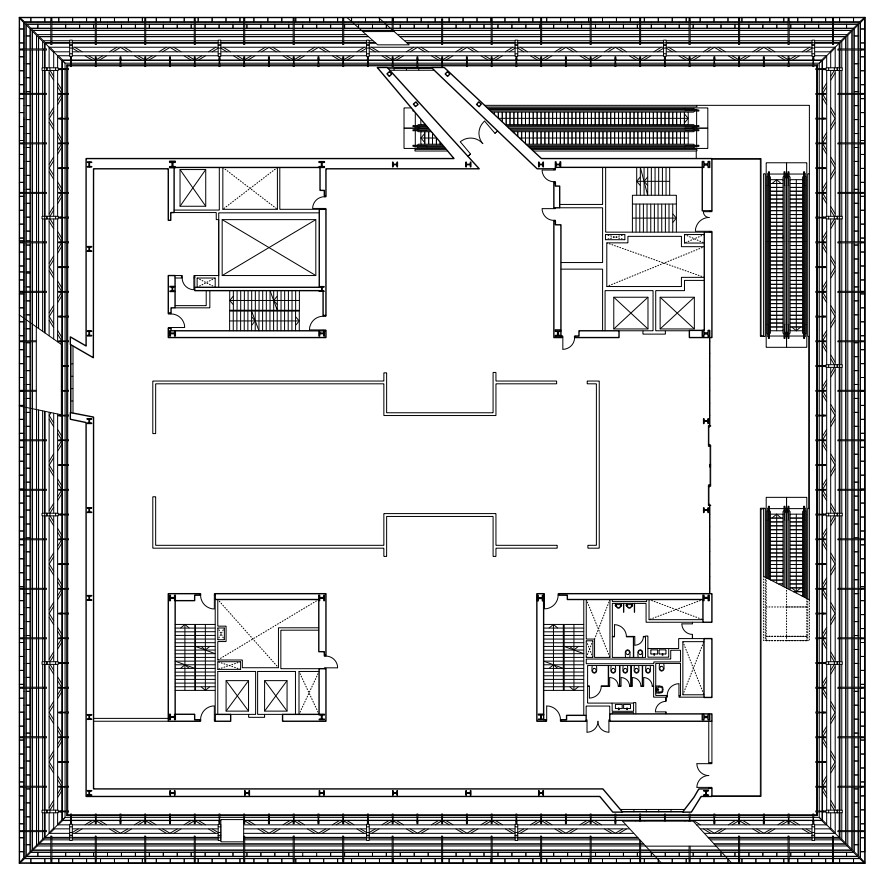

Planta cuarto nivel / Fourth floor plan

E. / S. 1: 750

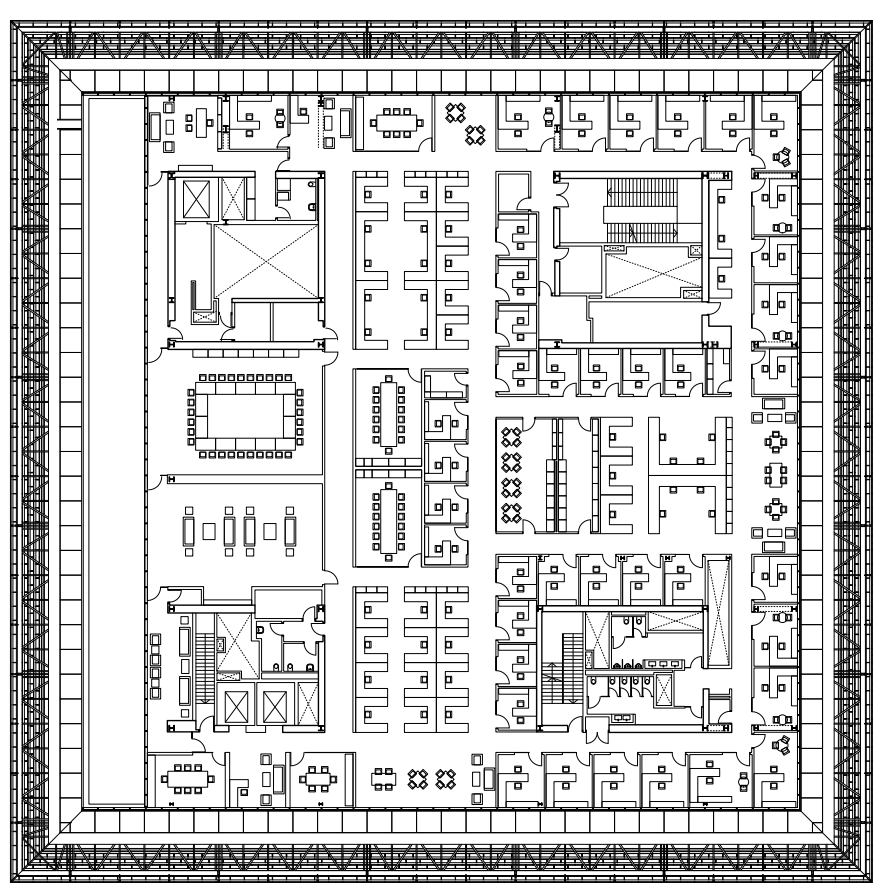



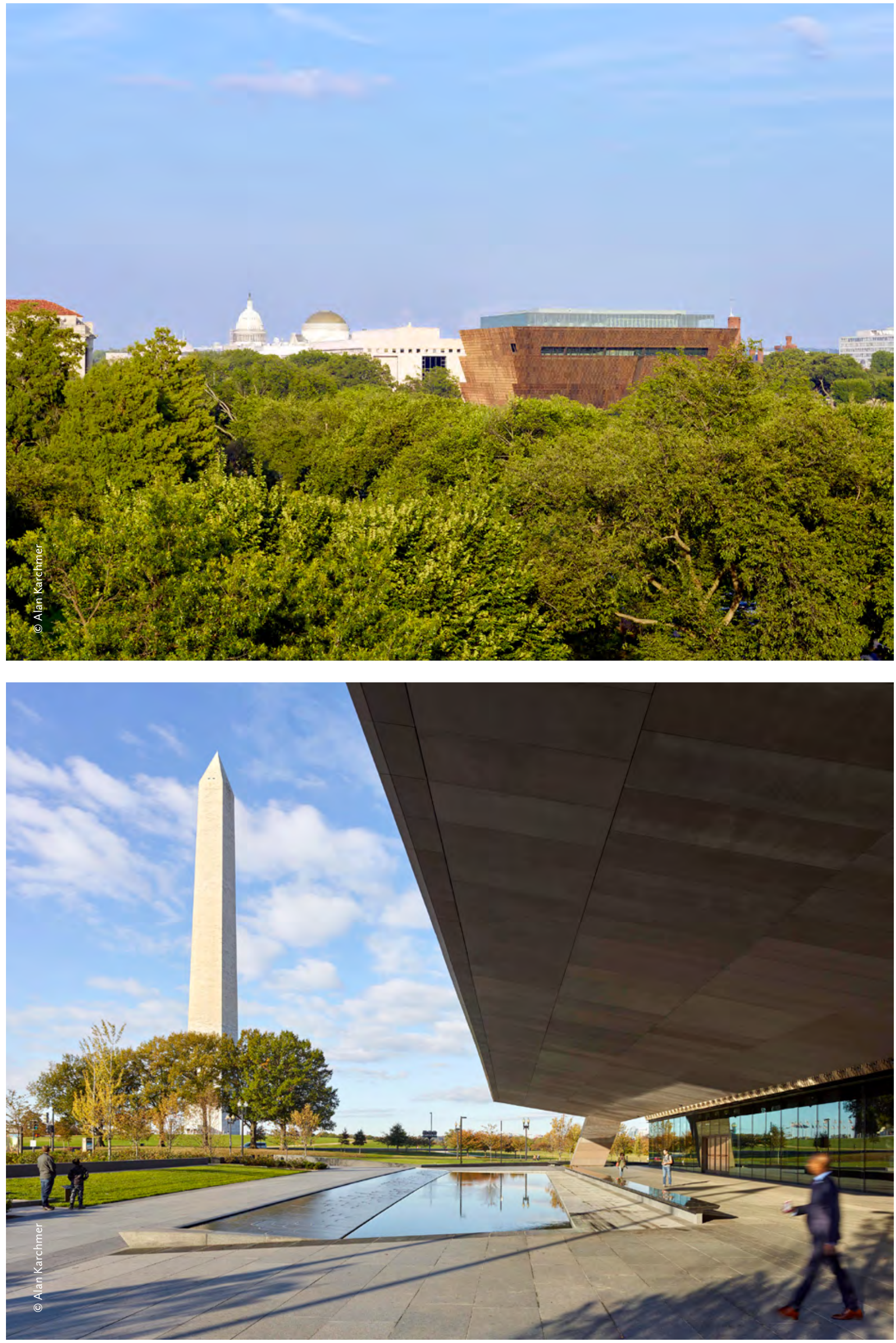

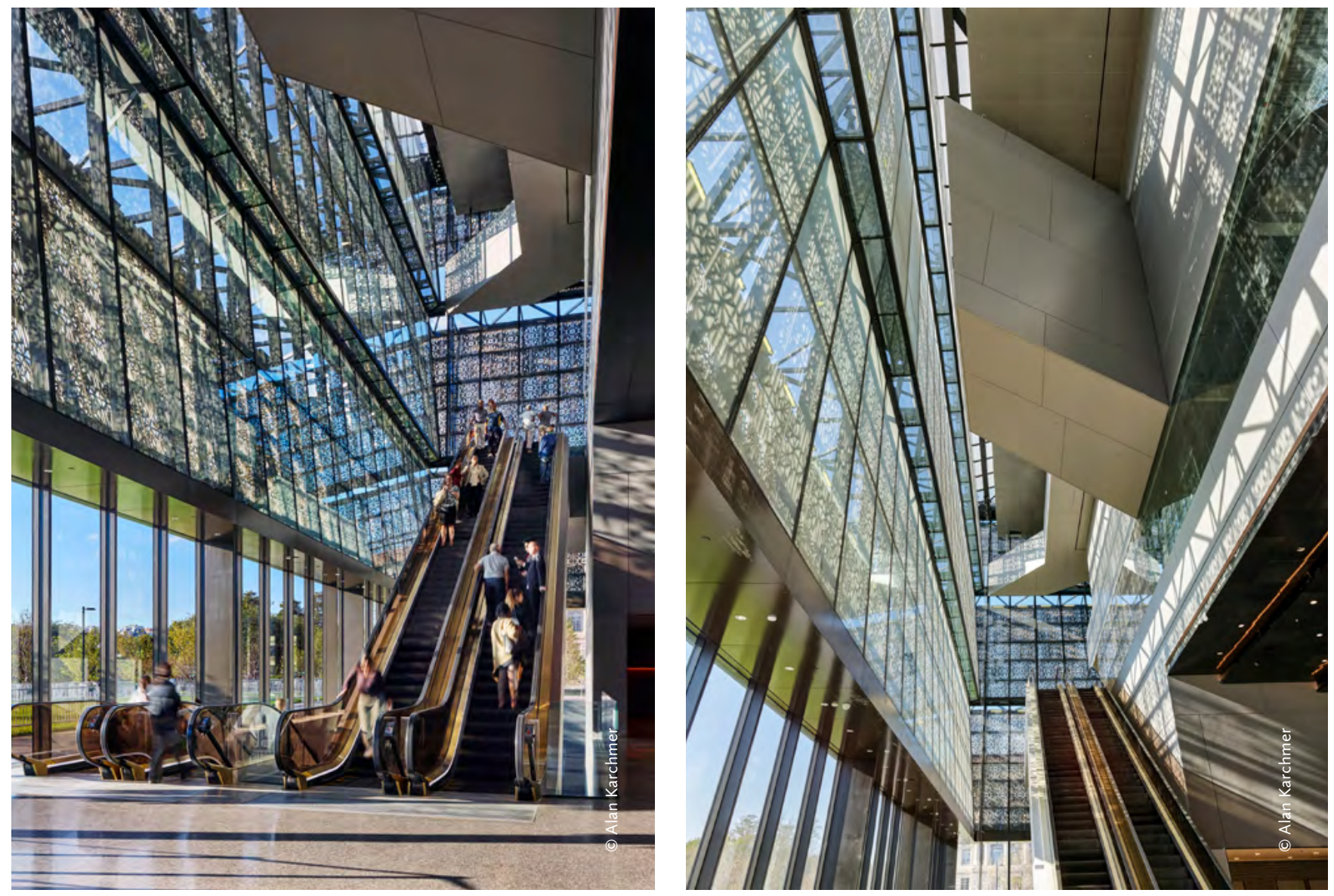

an extension of the building out into the landscape, the porch creates an outdoor room that bridges the gap between the interior and exterior.

At 50 meters deep, the setback is similar to other buildings on the north side of the Mall. The underside of the porch roof is tilted upward allowing reflection of the moving water below. This covered area creates a microclimate where breezes combine with the cooling waters to generate a place of refuge from the hot summer sun. There is also an outdoor patio that is accessed from the fifth floor of the building.

Inside the building, visitors are guided on a historical and emotional journey, characterized by vast, column-free spaces, a dramatic infusion of natural light, and a diverse material palette comprising pre-cast concrete, timber and a glazed skin that sits within the bronze-coated aluminum lattice. Below ground, the ambience is contemplative and monumental, achieved by the triple height history gallery and symbolized by the memorial space - the 'oculus' that brings light diffused by a cascade of water into the contemplative space. Moving upwards, the views become pivotal as one circulates along the corona with unrivalled panoramas of the Mall, Federal Triangle buildings and Monument grounds. ARQ 


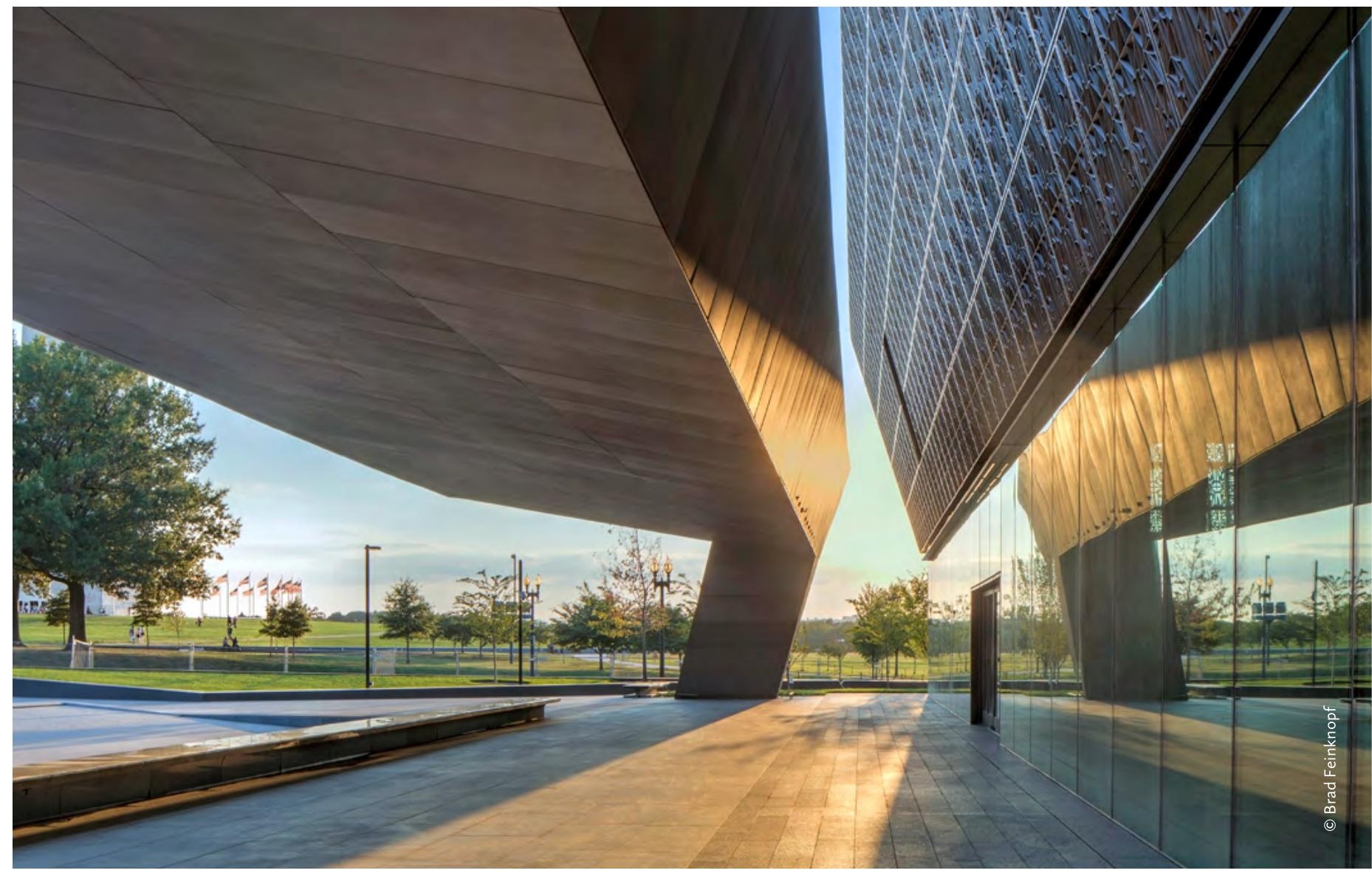

MUSEO NACIONAL SMITHSONIANO DE HISTORIA Y CULTURA AFROAMERICANAS SMITHSONIAN NATIONAL MUSEUM OF AFRICAN AMERICAN HISTORY AND CULTURE

Arquitectos / Architects: Adjaye Associates

Firmante / Architect of record: Freelon Group

Colaboradores / Contributors: Davis Brody Bond, SmithGroup JJR Ubicación / Location: Constitution Avenue, Washington DC Cliente / Client: Smithsonian Institution

Cálculo estructural / Structural engineering: Guy Nordeson and Associates, Robert Silman Associates

Ingeniería mecánica / Mechanical engineer: ws P Flack + Kurtz Asesoría de sustentabilidad / Sustainability Consultant: Rocky Mountain Institute
Asesoría de iluminación / Lighting consultants: Fisher Marantz Stone Paisaje / Landscape: Gustafson Guthrie Nichol

Asesoría multimedia y acústica/ Multi-media and acoustics consultants: Shen Milson Wilke

Asesoría de fachada / Facade consultant: RA Heintges \& Associates Asesoría de seguridad / Security consultants: ARUP North America Superficie de terreno / Site area: $420.000 \mathrm{ft}^{2}$

\section{Adjaye Associates}

$<$ press@adjaye.com>

Adjaye Associates was established in June 2000 by Founder and Principal, Sir David Adjaye овE. The firm has offices in Accra, London, and New York and works across Europe, North America, the Middle East, Asia, and Africa. The practice's largest commission to date, the Smithsonian National Museum of African American History and Culture, opened in 2016 on the National Mall in Washington DC. Among their projects it's worth noting the Ethelbert Cooper Gallery of African and African American Art at the Hutchins Centre, Harvard University (2014); the Nobel Peace Centre in Oslo (2005), and the UK National Holocaust Memorial and Education Centre in London, which is currently in development. 